\title{
Across-column cracks and axial splits in S2 saline ice under compression
}

\author{
E. M. Schulson, S. Qi, J. S. Melton, E.T. Gratz \\ Thayer School of Engineering, Dartmouth College, Hanover, New Hampshire 03755, U.S.A.
}

\begin{abstract}
Experiments on plate-like specimens have established that acrosscolumn cracks form within S2 (columnar) salt-water ice when compressed uniaxially along a direction inclined to the long axis of the grains. Wing cracks initiate from the across-column cracks and lengthen into axial splits when the ice is rapidly deformed; correspondingly, the macroscopic behavior changes from ductile to brittle. The acrosscolumn cracking is attributed to grain-boundary sliding, and the splitting to the suppression of crack-tip creep.
\end{abstract}

\section{INTRODUCTION}

The nucleation, propagation and interaction of cracks are important processes in the behavior of ice under compression (Schulson, 1997). At lower deformation rates, cracks nucleate but do not propagate; correspondingly, the material exhibits macroscopically ductile behavior. At higher rates, the cracks grow and interact; macroscopic faults eventually develop and brittle failure ensues.

Grain-boundary sliding has now been identified as an important mechanism of crack nucleation. Following earlier suggestions by Sinha $(1979,1984)$, recent experiments and calculations (Picu and others, 1994; Nickolayev and Schulson, 1995; Picu and Gupta, 1995a, b; Elvin and Sunder, 1996; Weiss and others, 1996) point rather conclusively to this mechanism as an effective means for concentrating stress. The experimental evidence is localized decohesion which precedes crack nucleation (Nickolayev and Schulson, 1995; Picu and Gupta, 1995b). The decohesion is manifested as sub-millimeter sized zones of opacity which are particularly distinct when columnar-grained ice is loaded along a direction inclined to the long axis of the grains (Nickolayev and Schulson, 1995). In that case, the sliding nucleates acrosscolumn cracks which may then initiate wing cracks along the loading direction. That grain-boundary sliding operates in ice at ambient temperatures is not surprising, given its well-recognized occurrence in hot polycrystalline metals (Zener, 1948).

The observations noted above were made specifically on fresh-water ice. It is assumed that the conclusions drawn apply also to salt-water ice, for the qualitative aspects of its deformation and the mechanisms invoked to explain its behavior are essentially identical (Smith and Schulson, 1994; Schulson and Nickolayev, 1995; Gratz and Schulson, 1997. However, the grain boundaries in salt-water ice are somewhat interdigitated, owing to its brine content. The question is whether the interdigitation impedes sliding to the point that crack nucleation is suppressed. This paper addresses this issue.

\section{PROCEDURE}

A sheet of S2 saline ice was unidirectionally grown in the laboratory in the manner described by Smith and Schulson (1994). The ice had the same characteristics as described earlier: $c$ axes randomly oriented within the horizontal plane; salinity of $4.3 \pm 0.7 \mathrm{ppt}$; density of $907 \pm 3 \mathrm{~kg} \mathrm{~m}^{-3}$; porosity of $4-5 \%$; average column diameter of about $8 \mathrm{~mm}$; spacing of $0.5-1 \mathrm{~mm}$ between platelet-like arrays of brine pockets. Plate-shaped specimens $(100 \mathrm{~mm} \times 50 \mathrm{~mm} \times$ $6 \mathrm{~mm}$ ) were cut from the sheet and then compressed at a constant strain rate between stainless-steel platens using a servohydraulic loading frame housed within a cold room. The temperature was $-10 \pm 0.2^{\circ} \mathrm{C}$, and the strain rate was either $1 \times 10^{-4} \mathrm{~s}^{-1}$ or $3 \times 10^{-3} \mathrm{~s}^{-1}$. The long axes of the columnar grains were parallel to the largest faces of the specimens and were inclined at about $45^{\circ}$ to the direction of loading. This orientation was selected to maximize the shear stress on the grain boundaries. The ice was observed and photographed (at the lower deformation rate) while shortening.

Salt-water ice is less transparent than fresh-water ice, owing to its porosity. To enhance the detection of grainboundary decohesion, additional observations were made using thinner specimens $(50 \mathrm{~mm} \times 50 \mathrm{~mm} \times 3 \mathrm{~mm})$. These specimens were also deformed at $-10^{\circ} \mathrm{C}$, at $10^{4} \mathrm{~s}^{-1}$.

\section{RESULTS AND OBSERVATIONS}

More than a dozen experiments were performed. The results were qualitatively reproducible and may be summarized as follows:

(i) The ice was macroscopically ductile at the lower rate and brittle at the higher rate. Figure 1 shows typical stress-strain curves.

(ii) At the lower strain rate, cracks were detected near the peak stress. They occurred in approximately parallel 

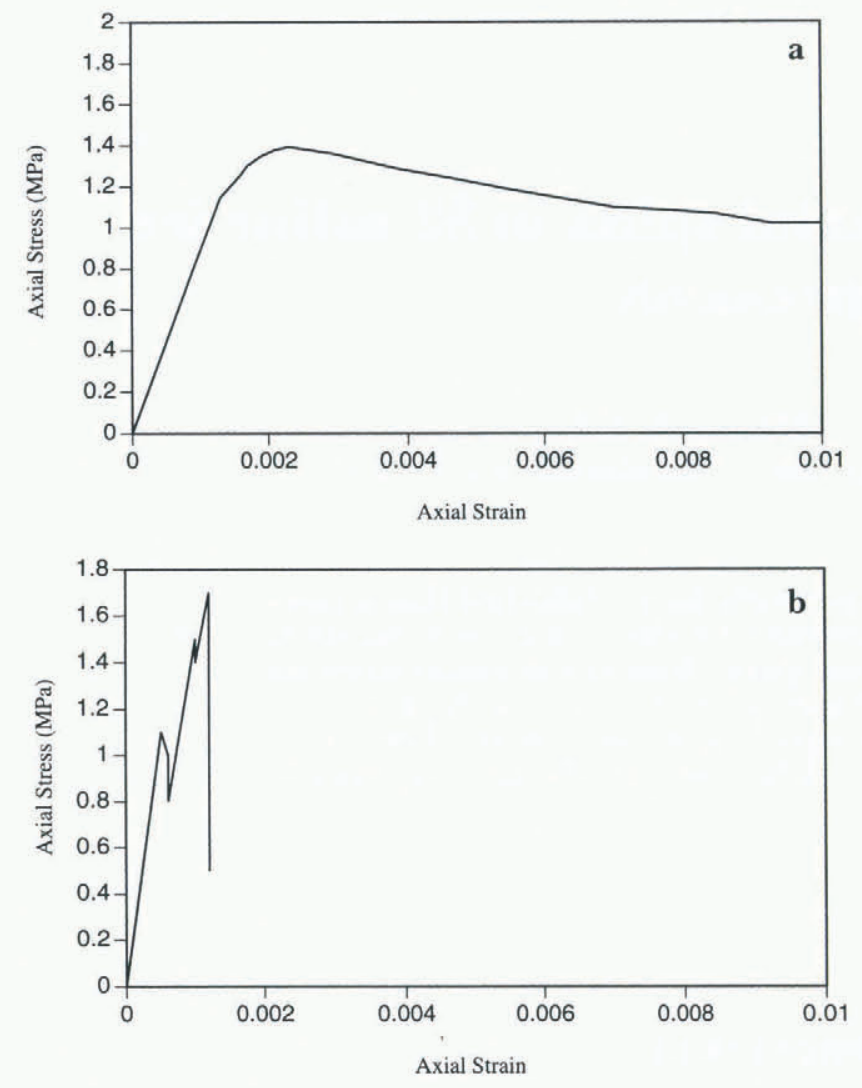

Fig. 1. Stress-strain curves for $S 2$ saline ice compressed uniaxially along a direction at about $45^{\circ}$ to the long axis of the columnar grains at $-10^{\circ} \mathrm{C}$ at strain rates of (a) $1 \times 10^{4} \mathrm{~s}^{-1}$ and (b) $3 \times 10^{-3} s^{-1}$. The curves indicate ductile and brittle behavior, respectively.

sets. Within a set, many of the cracks appeared to traverse a grain and to have both initiated and terminated at the grain boundaries, running more or less perpendicular to them. Figure 2 shows an example. Although difficult to see owing to the opacity of the ice, the grain boundaries in Figure 2 are defined by the lines joining the tops and the bottoms of the grain-sized cracks in a set.

(iii) At the higher strain rate, cracks formed across the grains, as at the lower rate, and then propagated along the direction of loading, splitting the specimen. Figure 3 shows an example. In the case illustrated, two of us (E.M.S. and S.Q.), while standing beside the deforming specimen, observed the split to extend from the tip of an across-column crack (which had formed during the test) and to run from the top to the bottom of the specimen. A piece of the ice to the left of the crack fell off the specimen along a grain boundary (Fig. 3, top center).

(iv) Fewer across-column cracks formed at the higher strain rate than at the lower rate. Presumably, they were stabilized against propagation at the lower rate by extensive crack-tip creep.

Both the across-column cracks and the axial splits are almost identical to the features observed in S2 fresh-water ice (Nickolayev and Schulson, 1995). The difference is that the cracks within the fresh-water material were preceded by the clear development of the decohesive zones on the grain boundaries, easily detectable by the unaided eye. Owing to the opacity of the saline ice, we were unable to

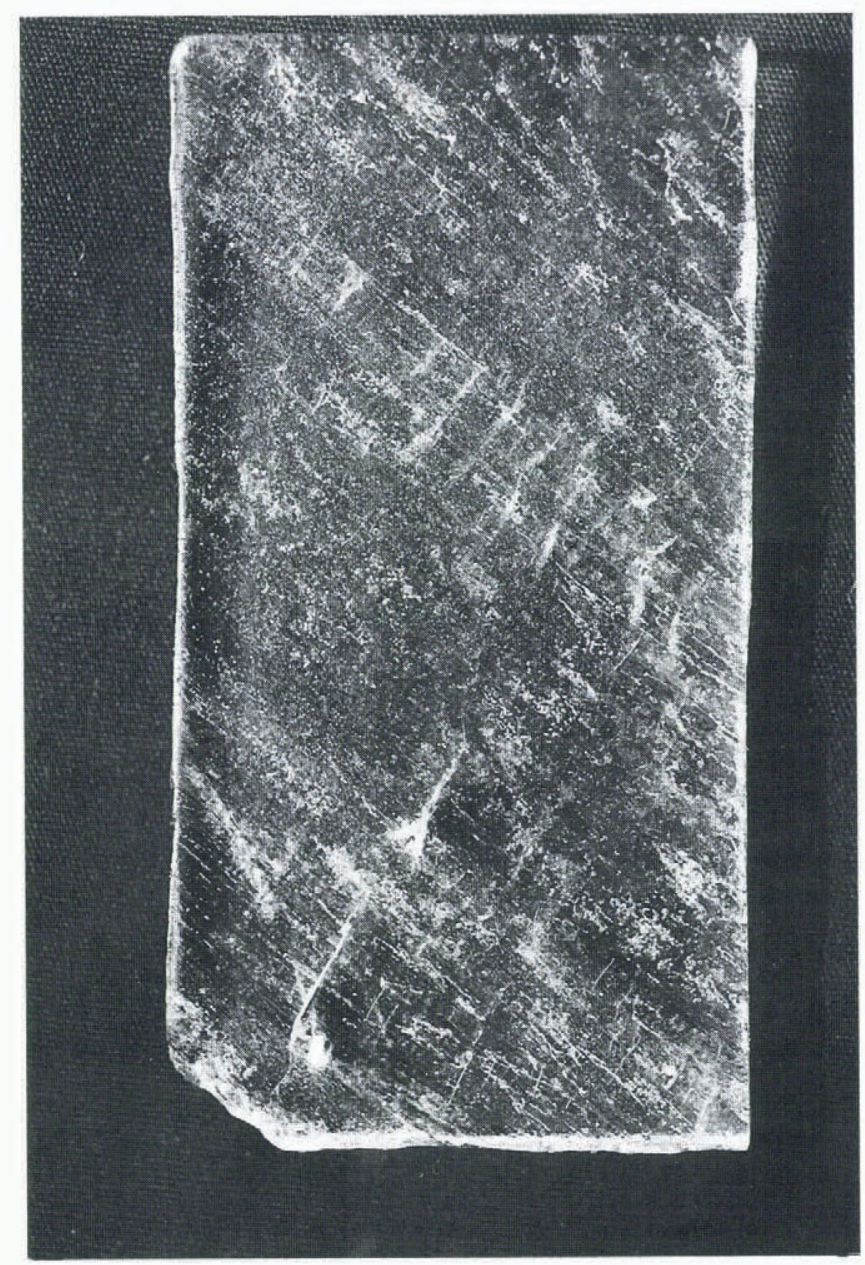

Fig. 2. Photograph showing across-column cracks in a specimen shortened $0.2 \%$ at $1 \times 10^{-t} s^{-1}$. The load was applied in the vertical direction. Note the sets of cracks which appear to have traversed a grain and to have initiated and terminated at the boundaries. Scale: specimen width $=50 \mathrm{~mm}$.

discern unambiguously whether localized grain-boundary decohesion also preceded the across-column cracking in this material. However, the deformed boundaries from which sets of across-column cracks emanated were somewhat milkier in appearance after the deformation, a feature more evident in the thinner specimens. This point and the fact that a piece of a specimen deformed at the higher rate broke free along the grain boundary from which an across-column crack nucleated suggest that some grain boundaries truly had lower cohesion after the deformation.

\section{DISCUSSION}

We again invoke grain-boundary sliding. In so doing, we assume that the boundaries act like mode-II cracks. Upon sliding, they concentrate stress at microstructural impediments, such as ledges or steps. When the stress there is high enough, the tensile component nucleates cracks which then tend to run across the columns, traversing the grain (presumably) where the stress is more highly concentrated. A relatively regular array of impediments would then account for the more-or-less uniformly spaced cracks within the sets.

The resistance to across-column crack propagation, $K_{\text {ap }}$, may be estimated as follows. If it is assumed that the cracks propagate when the mode-I stress intensity factor 


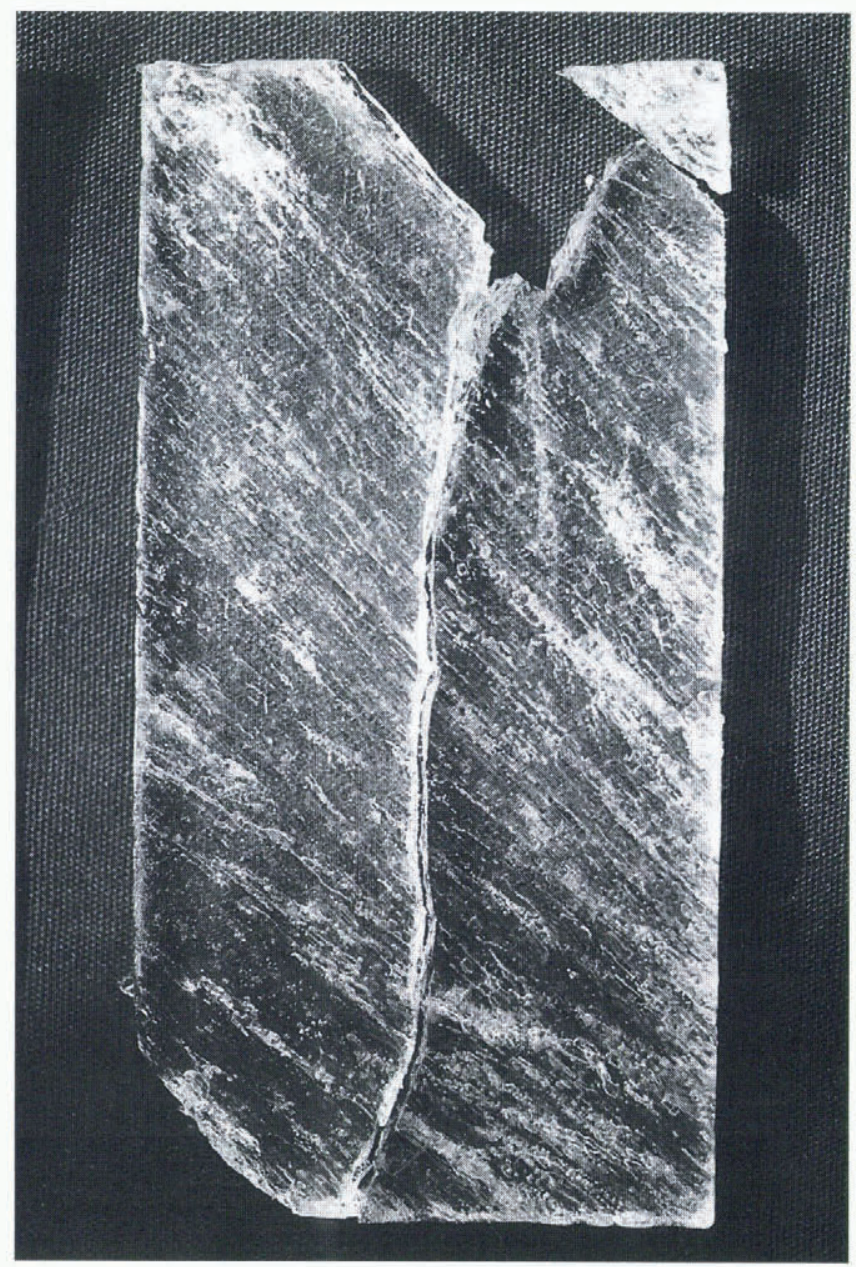

Fig. 3. Pholograph showing an across-column crack and an axial split in a specimen compressed at $3 \times 10^{-3} \mathrm{~s}^{-1}$. The load was applied in the vertical direction. The split ran from the top to the bottom of the specimen and appears to have initiated from the across-column crack. A piece of the ice fell off the specimen along a grain boundary (top center). Scale: specimen width $=50 \mathrm{~mm}$.

for very short out-of-boundary extensions reaches a critical value, then from Cotterell and Rice (1980):

$$
K_{\text {ap }}=2\left(\tau_{\mathrm{a}}-\tau_{\mathrm{b}}\right)\left(\frac{\pi l}{3}\right)^{\frac{1}{2}}
$$

where $2 l$ is the length of the boundary segment between the sliding impediments, $\tau_{\mathrm{a}}$ is the applied shear stress on the grain boundary and $\tau_{\mathrm{b}}$ is the intrinsic resistance to sliding. Upon substituting $2 l=3 \mathrm{~mm}$ (Fig. 2) and $\tau_{\mathrm{a}}=1.4 / 2 \mathrm{MPa}$ (Fig. 1) and by assuming that $\tau_{\mathrm{b}}=0$, we obtain $K_{\text {ap }}=$ $55 \mathrm{kPa} \mathrm{m}^{\frac{1}{2}}$. This value compares roughly with that deduced for fresh-water ice from the same kind of experiment (35 $\mathrm{kPa} \mathrm{m}^{\frac{1}{2}}$; Nickolayev and Schulson, 1995) and is similar to the apparent fracture toughness of sea ice $\left(25-80 \mathrm{kPa} \mathrm{m}^{\frac{1}{2}}\right)$ measured at the same scale but at $-2^{\circ} \mathrm{C}$ (Urabe and others, 1980). However, these values are lower than those obtained in the field on larger specimens where the apparent fracture increases with size and reaches about $250 \mathrm{kPa} \mathrm{m}^{\frac{1}{2}}$ for plates $80 \mathrm{~m}$ on edge (Dempsey, 1996).

The reason the across-column cracks stop when they reach the grain boundaries in the more slowly deformed ice, but generate out-of-plane extensions or wings which lengthen into splits in the more rapidly deformed material, is probably related to the rate of crack-tip stress relaxation. The argument and analysis are given elsewhere (Schulson, 1990). In essence, once the applied strain rate exceeds a certain level, there is insufficient time for crack-tip creep to reduce the mode-I stress intensity factor of the across-column crack to below its critical value. Wing cracks then sprout and lengthen along the direction of loading with increased applied stress, developing into full axial splits. Figure 4 sketches the sequence as it applies in the present case. The strain rate at which wing-crack growth occurs marks the ductile-to-brittle transition. For saline ice of the kind examined here, the transition rate at $-10^{\circ} \mathrm{C}$ has been both calculated and measured to be around $1 \times 10^{-3} \mathrm{~s}^{-1}$ (Schulson and Nickolayev, 1995), in agreement with the behavior apparent from the present tests.

The resistance to the propagation of the wing crack, $K_{\text {wp }}$, may be estimated from Ashby and Hallam's (1986) model of brittle compressive failure. The analysis incorporates frictional sliding of a parent crack which, in this case, is the across-column crack. Accordingly (Schulson, 1990):

$$
K_{\mathrm{wp}}=\frac{\sigma_{\mathrm{f}}(1-\mu)(2 a)^{\frac{1}{2}}}{Z}
$$

where $\sigma_{\mathrm{f}}$ is the fracture stress, $\mu$ is the ice/ice-friction coefficient, $2 a$ is the length of the across-column crack and $Z$ is an experimental constant. Upon substituting $\sigma_{\mathrm{f}}=1.7 \mathrm{MPa}$ (Fig. 1), $\mu=0.5$ (Jones and others, 1991), $2 a=10 \mathrm{~mm}$ (Fig. 2) and $Z=2$ (Schulson, 1990) we obtain $K_{\mathrm{wp}}=35 \mathrm{kPa} \mathrm{m}^{\frac{?}{2}}$.
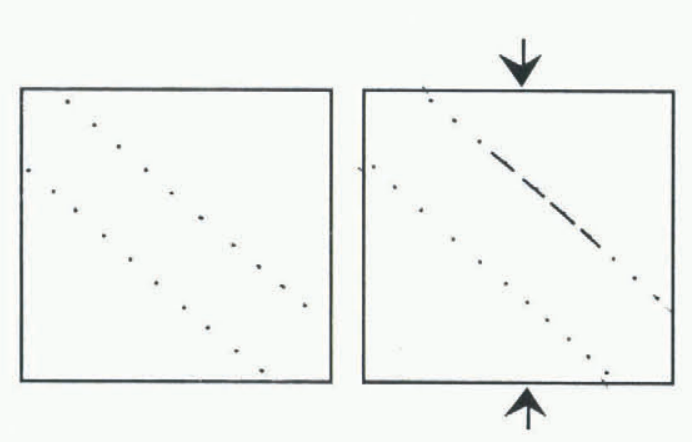
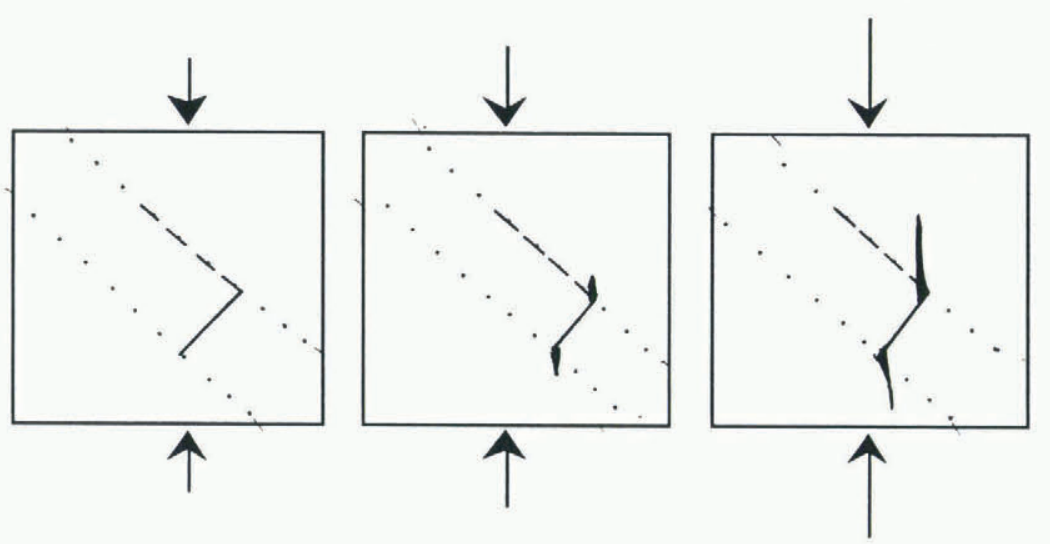

Fig. 4. Schematic sketches illustrating the development of an across-column crack (c) and an axial split (e) in columnar ice uniaxially compressed along a direction inclined to the long axis of the columnar grains. Dotted lines indicate grain boundaries; dashed lines indicate decohesion on one of the grain boundaries an across-column crack forms $(c)$; wing cracks initiate from the across-column crack (d) and then develop into axial splits ( $e$ ); 
Again this estimate is similar to the apparent fracture toughness of small specimens (Urabe and others, 1980).

\section{CONCLUSIONS}

It is thus concluded:

(i) that across-column cracks nucleate in relatively small plates of S2 saline ice through along-column grainboundary sliding, just as in fresh-water ice; and

(ii) that the across-column cracks initiate wing cracks which develop into axial splits when the strain rate is sufficiently high to suppress stress relaxation at the crack tips.

In other words, the interdigitation of the grain boundaries in S2 saline ice appears not to impede along-column grainboundary sliding to the point that across-column cracking is suppressed.

\section{ACKNOWLEDGEMENTS}

The authors would like to acknowledge the anonymous reviewers for their helpful comments. This work was supported by U.S. Office of Naval Research grant No. N0001492-J-1279.

\section{REFERENGES}

Ashby, M. F. and S. D. Hallam. 1986. The failure of brittle solids containing small cracks under compressive stress states. Acta Metall. Materialia, $34(3), 497-510$.

Cotterell, B. and J. R. Rice. 1980. Slightly curved or kinked cracks. Int. J. Fract., 16, 155-169.
Dempsey, J. P. 1996. Scale effects on the fracture of ice. In Arsenault, R.J. and 6 others, eds. The Johannes Weertman Symposium. Warrendale, PA, TMS, 351-362.

Elvin, A. A. and S. Shyam Sunder. 1996. Microcracking due to grainboundary sliding in polycrystalline ice under uniaxial compression. Acta Metall. Materialia, 44(1), 43-56.

Gratz, E. T. and E. M. Schulson. 1997 Brittle failure of columnar saline ice under triaxial compression: the failure surface. f. Geophys. Res.,102(B3), 5091-5107.

Jones, D. E., F. E. Kennedy and E.M. Schulson. 1991. The kinetic friction of saline ice against itself at low sliding velocities. Ann. Glaciol., 15, 242-246.

Nickolayev, O.Y. and E. M. Schulson. 1995. Grain-boundary sliding and across-column cracking in columnar ice. Philos. Mag. Lett., 72(2), 93-97.

Picu, R. C. and V. Gupta. 1995a. Crack nucleation in columnar ice due to elastic anisotropy and grain boundary sliding. Acta Metall. Materialia, 43(10), 3783-3789.

Picu, R. C. and V. Gupta. 1995b. Observations of crack nucleation in columnar ice due to grain boundary sliding. Acta Metall. Materialia, 43(10), 3791-3797.

Picu, R. C., V. Gupta and H. J. Frost. 1994. Crack nucleation mechanism in saline ice. 7. Geophys. Res., 99 (B6), 11,775-11,786.

Schulson, E. M. 1990. The brittle compressive fracture of ice. Acta Metall. Materialia, 38(10), 1963-1976.

Schulson, E. M. 1997. The failure of ice under compression. J.Phys. Chem. $B, 101(32), 6254-6258$.

Schulson, E. M. and O.Y. Nickolayev. 1995. Failure of columnar saline ice under biaxial compression: failure envelopes and the brittle-to-ductile transition. 7. Geophys. Res., 100(B11), 22,383-22,400. (Correction, J. Geophys. Res., 101 (B3), 1996, 5659.)

Sinha, N. K. 1979. Grain boundary sliding in polycrystalline materials. Philos. Mag. A, 40(6), 825-842.

Sinha, N. K. 1984. Intercrystalline cracking, grain-boundary sliding, and delayed elasticity at high temperatures. F. Mater. Sci., 19(2), 359-376.

Smith, T. R. and E. M. Schulson. 1994. Brittle compressive failure of saltwater columnar ice under biaxial loading. F. Glaciol., 40(135), 265-276.

Urabe, N., T. Iwasaki and A. Yoshitake. 1980. Fracture toughness of sea ice. Cold Reg. Sci. Technol., 3(1), 29-37.

Weiss, J., E. M. Schulson and H. J. Frost. 1996. The nucleation of microcracks in ice cubes compressed equally on all boundaries. Philos. Mag. A, 73 (5), 1385.

Zener, C. S. 1948. Fracturing of metals. Cleveland, OH, American Society of Metals. 